\title{
ATUAÇÃO DA FONOAUDIOLOGIA NA ESTÉTICA FACIAL: RELATO DE CASO CLÍNICO
}

\section{Speech therapy performance ih the facial aesthetics: case report}

\author{
Carla Cristina Gonçalves dos Santos ${ }^{(1)}$, Maria Julia Pereira Coelho Ferraz (2)
}

\section{RESUMO}

Tema: estética facial. Procedimentos: por meio de anamnese e avaliação clínica, aplicou-se um protocolo de tratamento com manipulação funcional dos músculos mastigatórios faciais acompanhados de exercícios isométricos num total de 8 sessões semanais, durante 2 meses, sendo fotografados antes e após o tratamento. O objetivo foi caracterizar as modificações faciais do ponto de vista qualitativo avaliadas clinicamente após tratamento Fonoaudiológico, num enfoque etiológico de caráter biomecânico. Resultados: observou-se uma melhoria da simetria facial e funções relacionadas à biomecânica mandibular. Conclusão: sugere-se a importância da atuação fonoaudiológica no restabelecimento facial e funcional da motricidade oral com repercussões na diminuição das rugas, marcas de expressão e flacidez.

DESCRITORES: Rejuvenescimento; Estética; Face; Beleza; Fonoaudiologia

\section{INTRODUÇÃO}

Diante da complexidade do sistema estomatognatico, conhecimentos específicos de anatomia, fisiologia e das teorias de crescimento craniofacial são necessários e tornam-se indispensáveis para compreensão da esfera individual. O conhecimento sobre etiologia e aspectos clínicos é importante para entender os efeitos da função dos músculos mastigatórios e faciais sobre o sistema estomatognatico, servindo de base para o planejamento e compreensão das variações do desenvolvimento e suas relações com os resultados funcionais e estético ${ }^{1-4}$.

Estamos constantemente buscando novas fórmulas de beleza acompanhadas de saúde e qualidade de vida. Freqüentar uma academia, caminhar, contribuem para melhorar a performance corporal e mental. Mas, não é só o corpo que precisa de

(1) Fonoaudióloga; Estagiária do Centro de Pesquisa e Atendimento Odontológico para Pacientes Especiais da Faculdade de Odontologia de Piracicaba da Universidade Estadual de Campinas, CEPAE-UNICAMP, Campinas, SP.

(2) Cirurgiã Dentista; Pesquisadora colaboradora do Departamento de Odontologia Social da Faculdade de Odontologia de Piracicaba da Universidade Estadual de Campinas, UNICAMP, Campinas, SP.

Conflito de interesses: inexistente ginástica e alongamento. Afinal, um rosto flácido não combina com um bom condicionamento físico. Os músculos do complexo craniofacial também requerem cuidados e exercícios físicos bem orientados, além das funções estomatognáticas em equilíbrio.

As disfunções mastigatórias possuem uma etiologia multifatorial e caráter complexo, envolvendo as diversas áreas da saúde, cujo tratamento deve buscar a eliminação ou minimização do quadro sintomatológico provocado, buscando o equilíbrio natural. Existem vários fatores que influenciam a função mastigatória de forma a alterá-la. Esses fatores podem envolver alterações estruturais ou funcionais do sistema estomatognatico, que desencadeiam um desequilíbrio, do qual um dos sinais pode ser a disfunção mastigatória ${ }^{5}$. Outra função importante do sistema estomatognatico, é a respiração, é consenso na literatura que quando o padrão respiratório ocorre de maneira inadequada, fazendo o indivíduo o uso da respiração oral de suplência várias alterações podem ser associadas, inclusiva a beleza facial ${ }^{6}$.

Neste contexto, observa-se um estreito relacionamento entre as marcas e vincos de expressão ao redor da boca e o uso da musculatura oral, visto que rugas indesejáveis podem ser resultantes de posturas e movimentos repetidos realizados pela 
mastigação, deglutição, respiração e fala. Além disso, as rugas podem sofrer influência da tensão exagerada dos músculos da face ${ }^{7}$.

Torna-se importante entender que o mecanismo neuromotor da expressão facial se traduz pela contração dos músculos faciais para comunicar expressões, através de uma via motora involuntária (sistema extrapiramidal) acrescentada de um componente cerebelar que controla a harmonia e sinergismo dos músculos. A comunicação volitiva de um sorriso, por exemplo, pode ser espontânea diante de uma cena cômica (via extrapiramidal: núcleos da base e hipotálamo), mas pode também ser um sorriso social, voluntário (via piramidal). A exteriorização da atenção, concentração, ira, dor, surpresa, espanto, alegria, sofrimento, tristeza, desprezo, desdém, enfado, menospreza, enfim uma variedade de detalhes de expressões permitindo a interpretação. No entanto, esta expressão muitas vezes, pode tornar-se difícil, uma vez que o homem aprendeu com a hipocrisia a usar a face como máscara velando seus verdadeiros sentimentos ${ }^{8}$.

A análise da estrutura craniofacial humana é naturalmente assimétrica em alguns graus ${ }^{9}$. Numa visão frontal da face, por meio de fotografia, demonstrou-se que a expressão facial de pessoas saudáveis não é necessariamente simétrica ${ }^{9,10}$.

A eficiência dos exercícios isométricos na musculatura facial pode ser utilizada em favor da estética, visando diminuir a flacidez muscular, rugas e marcas de expressão. Observou-se que, a realização sistemática dos exercícios isométricos pelo período de três meses favoreceu a diminuição das rugas, marcas de expressão e flacidez facial, com variação do grau e localização da melhora ${ }^{11}$.

O território ocupado pela estética facial tem sido abordado há muito tempo por profissionais como fonoaudiólogos, esteticistas, dermatologistas, cirurgiões plásticos. O fonoaudiólogo sempre executou o tratamento na área de Motricidade Orofacial, motivado por patologias como: deglutição atípica, assimetria facial, paralisia facial, entre outras. Como a estrutura facial pode ser modificada pela função, uma harmonia entre anatomia e função contemplam o resultado no restabelecimento das funções orais ${ }^{12-14}$. Deste modo, a atuação da Fonoaudiologia torna-se relevante, pois o trabalho com o sistema estomatognático melhora a função e também a estética $^{15-17}$.

Este estudo tem como objetivo caraterizar as modificações faciais do ponto de vista qualitativo avaliadas clinicamente após o tratamento fonoaudiológico, num enfoque etiológico de caráter biomecânico.

\section{APRESENTAÇÃO DO CASO}

A voluntária recebeu todas as explicações previamente sobre o tratamento bem como exposição para fins de publicação cientifica das imagens por meio do termo de consentimento livre de esclarecido.

O estudo compreende a descrição de um caso clínico, iniciando com a anamnese, que procurou valorizar o que mais incomodava na face, qualidade de dieta, tratamento estético realizado ou não, presença de alergia, hábitos viciosos, e histórico médico.

Realizou-se exame clínico subjetivo da musculatura mastigatória e facial por meio da observação, palpação, resistência à tração para definição dos graus de flacidez (leve,moderado e profundo) rugas e marcas de expressão.

A voluntária foi fotografada antes e após o protocolo terapêutico com câmera digital Sony-Cyber shot de 5.0 mega pixel a $1,0 \mathrm{~m}$ de altura sobre 0 tripé, posicionado a $1,0 \mathrm{~m}$ da voluntária.

De acordo com a interpretação da anamnese e exame clínico, elaborou-se uma sequência de exercícios faciais associada ao Protocolo de Rejuvenescimento Facial Funcional (PRFF) baseado no protocolo estabelecido por Negrelli ${ }^{1}$. O PRFF consistiu basicamente nas seguintes manobras, sempre levando em consideração a resposta do paciente, ou seja, sempre aquém do relato de

Alongamento dos músculos elevadores: inclui os músculos mastigatórios masseteres, temporais e pterigóideos mediais, com o alongamento dos músculos mastigatórios pterigóideos laterais superiores que trabalham em conjunto com os demais em fechamento ${ }^{10}$. Nesta manobra, o paciente deitado em máxima intercuspidação, conscientizado de "não poder abrir a boca", o profissional exerce uma força leve, no máximo moderada, para baixo. Ao mesmo tempo gira as mãos para frente, tentando abrir. Numa segunda manobra, com a mandíbula em posição postural, pedir ao paciente para protruir (ativação do músculo pterigóideo lateral inferior direito e esquerdo e inativação dos feixes superiores, respectivamente), repetindo os movimentos da primeira manobra. Segue o alongamento dos músculos mastigatórios pterigóideos laterais inferiores: paciente em posição de repouso mandibular, pede-se para protruir com a menor força possível. O profissional atua com força igual no sentido contrário. Para o alongamento dos músculos pterigóideo lateral inferior, individualmente (esquerdo e direito), solicita-se ao paciente a posição postural e inicia o desvio da mandíbula para um lado, em que o profissional exerce força leve no sentido da linha média, soltando devagar. Repetir a manobra do lado oposto. 
- Alongamento dos músculos abaixadores supra e infra-hióideos. Consiste em solicitar ao paciente que permaneça com a língua na região das rugas palatinas, ciente de que não pode haver movimento, pede-se ao paciente a tentativa de abrir a boca com pouca força sendo impedida pelas mãos do profissional que estão apoiadas no corpo da mandíbula. Soltar lentamente. Cuidado deve ser tomado, pois esta manobra desloca muita tensão cervical.

- Manipulação dos músculos faciais: solicitar ao paciente para fazer bico e com as duas mãos deleitadas sobre as bandas superior, média e inferior do músculo bucinador direito e esquerdo, deslizar no sentido contrário do movimento. Após este, solicitar ao paciente para realizar o sorriso forçado ao mesmo tempo em que o profissional mantém apoiados os indicadores em nível de margem orbitária inferior de ambos os lados. Finalmente, solicita-se que o paciente feche os olhos e com os dedos indicador e polegar do profissional tente abrir os olhos do paciente, ao mesmo tempo em que o paciente os mantém fechados.

- Finaliza-se com a pompagem cervical realizada pelo profissional solicitando ao paciente para permanecer em posição postural de repouso mandibular:elevar a cabeça dois centímetros e girá-la para Direita , os dedos indicador e médio percorrem o músculo esternocleidomastóideo( ECM) do paciente de cima para baixo (repetir do outro lado).

- Com a mão esquerda elevar a cabeça do paciente: com o dedo indicador e médio em $\mathrm{V}$, percorrer o trapézio de cima para baixo.

Preconiza-se cerca de 30 a 40 segundos para cada manobra, objetivando o alongamento, observando e indagando sobre desconfortos e dores.

1. Com a boca fechada, fazer a letra "O".

2. Repetir o exercício número $1 \mathrm{com}$ a boca aberta.

3. Com a boca fechada, ponta da língua na papila, sorrir levantando o lábio superior alternadamente.

4. Segurar o hiperboloide ${ }^{11}$ na região do músculo bucinador do lado direito e esquerdo, alternadamente, contanto até 10 mentalmente.

5. Colocar as duas mãos sobrepostas na testa, comprimir, puxar a testa para cima, fechar os olhos olhando para baixo.

6. Abrir os olhos o máximo contando até 5 .

7. Esticar a cabeça para frente, endireitar os ombros, esticar o lábio inferior para cima, cobrindo o lábio superior fechando a boca.
Virar para o lado direito e esquerdo contando até 5.

8. Alongamento dos músculos de fechamento mandibular conforme PRFF.

9. Alongamento dos músculos de abertura mandibular conforme PRFF.

10. Girar os ombros para frente e para trás 3 vezes.

\section{Caso Clínico}

Paciente do gênero feminino com 47 anos, sem receber qualquer atendimento fonoaudiológico ou relacionado à estética facial. Observou-se queixas relacionadas à flacidez, rugas, olhar cansado e marcas de expressão tais como: assimetria facial, assimetria dos olhos estando a pálpebra esquerda mais flácida, narina esquerda mais fechada; filtro bem alongado, sulco nasolabial esquerdo mais acentuado; ambas bochechas flácidas (direita mais volumosa); cabeça levemente girada e inclinada; pescoço com flacidez (Figuras 1 e 2).

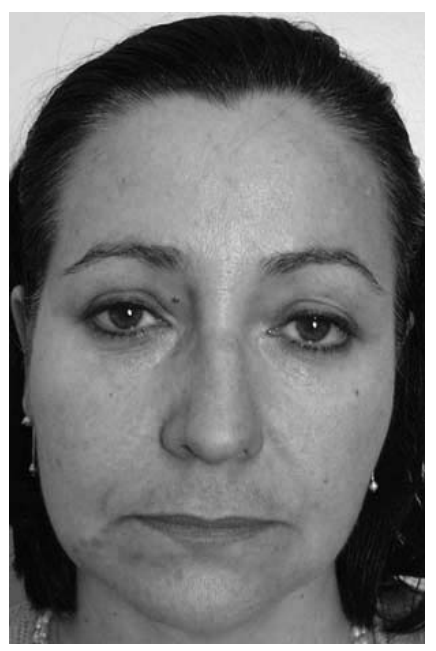

Figura 1

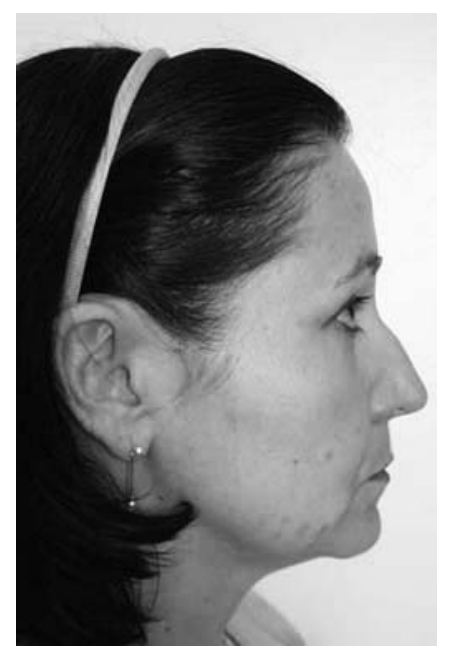

Figura 2 


\section{RESULTADOS}

Após o término do tratamento proposto, a voluntária relatou uma sensação de bem-estar com mudanças das situações funcionais tais como percepção visual da diminuição das rugas e marcas de expressão, além de relatar a facilidade de se exercitar com pouco tempo diário.

Clinicamente, observou-se uma melhoria na simetria de sobrancelhas e olhos, na tonicidade das pálpebras, na tonicidade do filtro, aumento da abertura da narina esquerda, contribuindo para diminuição da assimetria das narinas. O sulco nasolabial do lado direito e esquerdo estão menos assimétricos. Atentou-se, do ponto de vista qualitativo, para uma melhor adequação funcional na tonicidade e simetria das bochechas, na postura de cabeça e da tonicidade do pescoço (Figuras 3 e 4).

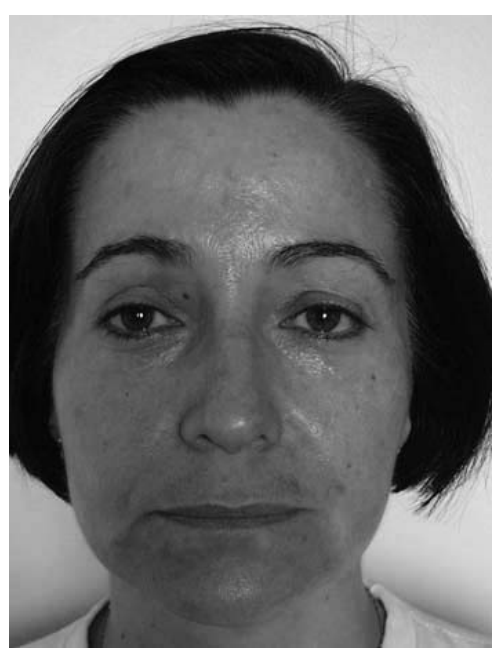

Figura 3

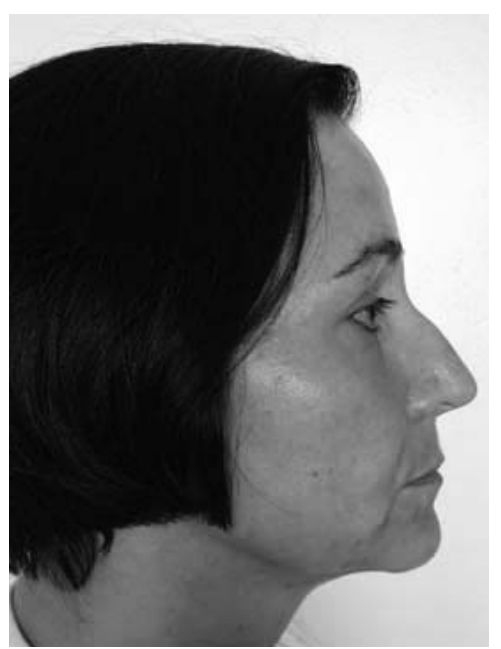

Figura 4

\section{DISCUSSÃO}

Estamos constantemente buscando novas fórmulas de beleza acompanhadas de saúde e qualidade de vida. Mas o que é o belo? Câmara(2006) ${ }^{18}$ reportou que beleza é a forma que o amor dá as coisas e é estético aquilo que tem característica de beleza. Percebe-se que é uma definição subjetiva não permitindo que se leve em consideração para o diagnóstico e tratamento das disfunções do sistema estomatognático que também tem como objetivo uma melhor performance estética. Portanto, métodos para avaliar os resultados encontrados tornamse relevantes sendo aqui proposto a fotografia para caracterizar as modificações faciais do ponto de vista qualitativo avaliadas clinicamente após o tratamento fonoaudiológico.

A musculatura da face, do pescoço e do colo também requerem cuidados e exercícios físicos bem orientados. Isso porque os músculos faciais são os mais delicados e frágeis do corpo humano, inserindo-se diretamente na cútis e mucosa ${ }^{8} \mathrm{e}$ estão funcionalmente relacionados com a alimentação, a mastigação, a fonação, a respiração, o piscar dos olhos, etc. A sua contração movimenta a pele do rosto e produz a depressão que com o tempo se transforma-se em ruga e sulco.

Se retornarmos há alguns anos, verificou-se que o homem para satisfazer suas necessidades nutritivas, utilizava-se das mãos para apreensão do alimento e da boca para a mastigação dos mesmos. Não tínhamos a facilidade "aparente" do cozimento, dos liquidificadores, dos microondas, que hoje facilitam o nosso cotidiano. No entanto, esta modernidade aparente interfere no desempenho de várias funções do nosso organismo, dentre elas a falta de estímulo para o desenvolvimento adequado do complexo craniofacial $^{1-4,19}$, com repercussões na expressão facial. Além do mais, estamos sufocando nosso dia a dia com mil tarefas e conseqüentemente uma bateria de tensões nervosas acabam descarregando em nosso semblante facial. Nossa face é a porta de entrada do mundo. Nossa boca é o coração da face. Todo registro de emoções seja de alegria ou tristeza, de saúde ou de dor, de preocupação, de depressão ficam estampadas em nosso rosto. Assim, os movimentos carregados de estresse agravam os sulcos e as rugas, levando a um envelhecimento precoce.

Uma vez que a terapia fonoaudiológica é um método de tratamento que pode aumentar a força muscular do sistema estomatognático, podendo devolver a estabilidade morfo-funcional às estruturas orofaciais e conseqüentemente a estética ${ }^{20}$, a incorporação de protocolos de adequação funcional facial com exercícios orientados na rotina diária 
torna-se importante para que os resultados favoráveis persistam.

O tempo de duração total deste tratamento foi de dois meses (8 sessões semanais) associados a exercícios isométricos da face corroborando os tempos de tratamentos propostos na literatura que variaram de cinco sessões ${ }^{7}$, três meses com 12 sessões ${ }^{13}$, a cinco meses com 20 sessões ${ }^{14}$.

No entanto novos estudos de natureza quantitativa tornam-se necessários para avaliar a duração destes benefícios bem como a acomodação das fibras musculares no estabelecimento de um novo comprimento muscular adaptativo com reflexos positivos na estética e função oral.

O presente estudo demonstrou que a realização sistemática do Protocolo de PRFF contribuiu para a diminuição das rugas, melhoria da simetria facial e funções relacionadas a biomecânica mandibular, colaborando com uma estética facial mais favorável.

\section{CONCLUSÃO}

Sugere-se a importância da atuação fonoaudiológica no restabelecimento funcional e estético.

\begin{abstract}
Background: aesthetics Procedures: by means of a questionnaire and clinical evaluation, we applied a treatment protocol with functional manipulation of the masticatory muscles accompanied by facial isometric exercises for a total of 8 weekly sessions during 2 months, and we photographed before and after treatment. This study aimed at featuring four facial changes in terms of quality, as assessed after treatment, under an etiological and biomechanical character focus. Results: there was an improvement in facial symmetry and functions related to mandibular biomechanics. Conclusion: we suggest the importance of speech-language intervention in restoring facial and functional oral motor that influence the reduction of wrinkles, expression marks and flaccidity.
\end{abstract}

KEYWORDS: Rejuvenetion; Esthetics; Face; Beauty: Speech, Language and Hearing Sciences

\section{REFERÊNCIAS}

1. Coelho-Ferraz MJP, Bérzin F, Colletes Alves LM, Cheida AP. Avaliação eletromiográfica das desordens mastigatórias em pacientes submetidos à Facilitação Neuromastigatória Manipulativa Negrelli associada: relato de caso clínico. RGO. 2007; 55(3):17-22.

2. Coelho-Ferraz MJP, Nouer DF, Bérzin F, Sousa MA, Romano F. Cephalometric appraisal of the hyoid triangle in Brazilian people of Piracicaba's region. Braz J Oral Sci. 2006; 5(17):1001-6.

3. Coelho-Ferraz MJP, Bérzin F, Amorim C. Electromyography evaluations of the masticator muscles during the maximum bite force. Rev Esp Cir Oral Maxilofac. 2008; 30(6):420-7.

4. Coelho-Ferraz MJP, Bérzin F, Amorim C, Queluz D.P. Electromyographic Evaluation of Mandibular Biomechanic, Int. J. Morphol.2009; 27(2):485-90.

5. Whitaker ME, Trindade Júnior AS, Genaro KF, Proposta de protocolo de Avaliação Clínica da Função Mastigatória, Rev. CEFAC [online]. ahead of print, pp. 0-0. Epub 15-Maio-2009. ISSN 1516-846.
6.Ferla A, Silva AMT, Corrêa ECR. Atividade eletromiográfica dos músculos temporal anterior e masseter em crianças respiradoras bucais e em respiradoras nasais. Rev Bras Otorrinolaringol. 2008;74(4) :588-95.

7. Franco MZ. Estética facial: uma nova atuação fonoaudiológica. Informativo do Conselho Regional de Fonoaudiologia: $2^{\underline{a}}$ região. São Paulo: Conselho Regional de Fonoaudiologia; 2000. p. 15.

8. Madeira MC. Anatomia da face: bases anátomofuncionais para a prática odontológica. 2.ed. São Paulo: Sarvier; 1998.

9. Ferrario VF, Sforza C, Miani Junior A, Serrao G. A three-dimensional evaluation of human facial asymmetry. J Anatomy. 1995; 186(Pt 1):103-10.

10. Farkas LG, Cheung G. Facial asymmetry in healthy North American Caucasians. An anthropometrical study. Angle Orthod. 1981; 51(1):70-7.

11. Nakamura T, Okamoto K., Maruyama T. Facial asymmetry in patients with cervicobrachial pain and headache. J Oral Rehabil. 2001; 28(11):1009-14.

12. Cheida AP. Hiperboloide instrumento de mastigação: um estimulador periomiofuncional. São Paulo: Ícone; 2004.p. 55-64. 
13. Takacs AP, Valdrighi V, Assencio-Ferreira VJ. Fonoaudiologia e estética: unidas a favor da beleza facial. Rev CEFAC. 2002; 4(2):111-6.

14. Tasca SMT. Programa de aprimoramento muscular em fonoaudiologia estética facial (PAMFEF). Barueri: Pró-fono; 2002. 186 p.

15. Paes MCNM. Estética facial e voz: uma nova interface. [monografia]. Recife (PE): Universidade Federal de Pernambuco; 2004. 67 p.

16. Paes C, Toledo PN, Silva HJ, Fonoaudiologia e Estética Facial: Estudos de Casos, Rev CEFAC. 2007 abr-jun; 9(2):213-20.

17. Souza EMB, Morais WMB, Silva HJ, Cunha DA, O conhecimento do Fonoaudiólogo Especialista em
Motricidade Oral Sobre Atuação em Estética Facial. Rev CEFAC. 2005 jul-set;7(3): 348-18. Camara CALP da. Estética em Ortodontia: Diagramas de Referências Estéticas Dentárias( DRED) E Faciais(DREF0. Ver DENT Press Ortodon Ortop Facial. 2006 dez; 11(6): 130-56.

19. Ferraz MJPC, Nouer DF, Teixeira JR, Bérzin F. Avaliação cefalométrica da posição do osso hióide em crianças respiradoras bucais. Rev Bras Otrorrinolaringol. $2007 \mathrm{fev}$; 73(1): 47-52.

20. Lessa FCR, Enoki C, Feres MFN, Valera FCP, Lima WTA, Matsumoto MAN. Influência do padrão respiratório na morfologia craniofacial. Rev Bras Otorrinolaringol. 2005 mar-abr; 71(2):156-60. 